\title{
Effect of Different Water Treatments in Soil-Plant-Atmosphere Continuum Based on Intelligent Weighing Systems
}

\author{
Hairong Gao ${ }^{1,2,3}$, Rui Guo ${ }^{2,3}$, Kaili Shi ${ }^{2,3}$, Huanfang Yue ${ }^{4}$, Shaoying Zu ${ }^{5}$, Zhiwei Li ${ }^{1, *}$ and Xin Zhang ${ }^{2,3, *}$ \\ 1 College of Agricultural Engineering, Shanxi Agriculture University, Jinzhong 030801, China; \\ gaohr66@163.com \\ 2 National Engineering Research Center for Intelligent Equipment in Agriculture, Beijing Academy of \\ Agriculture and Forestry Sciences, Beijing 100097, China; guor@nercita.org.cn (R.G.); skaili_91@163.com (K.S.) \\ 3 Key Laboratory for Quality Testing of Hardware and Software Products on Agricultural Information, \\ Ministry of Agriculture, Beijing 100125, China \\ 4 Beijing Agricultural Technology Promotion Station, Beijing 100029, China; yuehuanfang@163.com \\ 5 Tianjin Agricultural Machine Technology Test Service Center, Tianjin 301616, China; chengdxoky@163.com \\ * Correspondence: lizhiweitong@163.com (Z.L.); zhangx@nercita.org.cn (X.Z.)
}

check for updates

Citation: Gao, H.; Guo, R.; Shi, K.; Yue, H.; Zu, S.; Li, Z.; Zhang, X. Effect of Different Water Treatments in Soil-Plant-Atmosphere Continuum Based on Intelligent Weighing Systems. Water 2022, 14, 673. https://doi.org/10.3390/w14040673 Academic Editor: Roberto Greco

Received: 20 January 2022

Accepted: 16 February 2022

Published: 21 February 2022

Publisher's Note: MDPI stays neutral with regard to jurisdictional claims in published maps and institutional affiliations.

Copyright: (C) 2022 by the authors. Licensee MDPI, Basel, Switzerland. This article is an open access article distributed under the terms and conditions of the Creative Commons Attribution (CC BY) license (https:// creativecommons.org/licenses/by/ $4.0 /)$.

\begin{abstract}
In order to meet the needs of dynamic continuous monitoring of soil-plant-atmosphere continuum (SPAC), a new soil, plant, atmosphere analysis system has been established based on an intelligent weighing system (IWS). Four types of irrigation treatments $(90 \%, 80 \%, 70 \%$, and $60 \%$ of field capacity (FC)) were conducted on lettuce (Lactuca sativa var. ramosa Hort.) for two-season planting experiments. Regarding the soil, the relative system weight of IWS showed a significant linear correlation with the soil volumetric moisture content (SWC) $\left(R^{2}=0.64-0.94\right)$. When the SWC increased by $1.00 \%$, the soil weight increased by 56-62 g. Regarding plants, the IWS also clearly reflected the changes in plant weight gain, transpiration rate, and stomatal conductance at different growth stages. After verification, the relative errors of the transpiration rate and stomatal conductance measured by the IWS were $-9.60-22.30 \%$ and $-7.20-22.20 \%$, respectively. Regarding the atmospheric environment, the variation trend of the crop evapotranspiration $\left(E T_{\mathcal{c}}\right)$ based on the IWS and the reference crop evapotranspiration $\left(E T_{0}\right)$ calculated with meteorological parameters were consistent. However, the numerical difference was in the uncertainty of the crop coefficient $\left(K_{c}\right)$. The $E T_{c}$ of lettuce under the $80 \%$ FC treatment was the highest. Accordingly, a daily online measurement method for $K_{\mathrm{c}}$ was established. The $K_{\mathrm{c}}$ values of lettuce at different growth stages were $0.88,1.22$, and 2.43, respectively. The growth, yield, and water use efficiency (WUE) of crops under $80 \%$ FC treatment compared with other treatments significantly increased by $11.07-21.05 \%, 0.91-9.89 \%$, and $2.16-15.80 \%$, respectively. Therefore, the $80 \%$ FC was adopted as the irrigation low limit of potted lettuce. The experimental results provide a theoretical basis for further guiding crop irrigation.
\end{abstract}

Keywords: IWS; online monitoring; SPAC; different water treatment

\section{Introduction}

In the SPAC water vapor dynamic circulation system, plants are the main link connecting soil and atmosphere [1-5]. Water reaches plant roots through soil, leaves through plant stems, then diffuses from leaf stomata to the static air layer, and finally participates in the atmospheric turbulent transformation to form a unified, dynamic, and mutual feedback continuous system [6,7]. Accordingly, the continuous monitoring of SPAC is of great significance for comprehensively exploring the law of crop water consumption.

Domestic and foreign scholars have conducted extensive research on SPAC. In the field of soil monitoring, Ekanayaka et al. [8] have developed low-cost capacitive soil moisture sensors for data collection, with the aim of automatically monitoring soil moisture. Shen et al. [9] used soil moisture sensors to measure the soil moisture content at different depths to determine the appropriate placement of soil moisture sensor. Stephan et al. [10] utilized 
soil moisture sensors to measure the soil moisture content at different locations and found that after rainfall, the soil moisture in the corridor was the lowest in the weathered surface crust. However, in practical application, the aforementioned methods can only obtain single-point parameters and cannot completely describe the state of the overall soil moisture loss in the root-zone during crop growth. In crop monitoring, a portable photosynthetic instrument is utilized to determine the transpiration rate, stomatal conductance and other indicators of cotton [11], hybrid winter wheat [12] and young apricot trees [13]. Current monitoring methods are mainly based on leaf-scale parameter information, and continuous online monitoring cannot be realized, thereby reducing the integrity of crop response research. Regarding atmospheric monitoring, Liu et al. [14] and Wang et al. [15] utilized a large-scale automatic weighing lysimeter to measure the actual crop evapotranspiration. Tyagi et al. [16] used a weighing lysimeter to measure the hourly evapotranspiration of rice and sunflowers. However, the equipment has high cost, complicated installation, and difficult soil borrowing process, thereby limiting its wide-scale application.

Based on this, we propose a low-cost potted plant evapotranspiration measurement system based on Lora wireless technology for horticultural facilities [17]. This system achieves the continuous weighing of potted plants in the whole growth cycle and realtime monitoring of the evapotranspiration of potted plants. As a kind of crop with large water demand and high sensitivity to water, vegetables are suitable for irrigation test based on our IWS. Lettuce (Lactuca sativa var. ramosa Hort.) as a representative of leafy vegetables, is rich in nutrition and has certain health and medicinal value. In recent years, the cultivation scale of lettuce has increased rapidly. The vegetable planting area in China is approximately 1.35 million $\mathrm{hm}^{2}$ [18]. Based on the IWS, this study monitors and analyzes the SPAC of lettuce under different water treatments, so as to explore the water consumption characteristics of potted crops under different water treatments. This study provides theoretical guidance for improving precise crop irrigation and provides a new direction for the development of irrigated agriculture.

\section{Materials and Methods}

\subsection{Test Materials}

This study conducted two cropping experiments in a sunlight greenhouse $\left(116^{\circ} 46^{\prime} \mathrm{E}\right.$, $40^{\circ} 18^{\prime} \mathrm{N}$ ) of the National Precision Agriculture Demonstration Base in Changping District, Beijing, at an altitude of $50 \mathrm{~m}$. Pot planting of lettuce (Lactuca sativa var. ramosa Hort.) was used in the experiments. Soil was obtained from 0-20 cm soil layer of the base farmland. After being naturally air dried it was crushed and passed through a 2-mm sieved soil. The soil type was sandy clay loam and the cultivated land quality grade is medium. The field water capacity was measured by the drying method, and the soil bulk density was measured by the Wilkes method [19]. The inner diameter of the pot used in the experiments was $29 \mathrm{~cm}$, and the height was $23 \mathrm{~cm}$. The pot was filled with $8 \mathrm{~kg}$ of air-dried soil. Before planting, $1.57 \mathrm{~g}$ of urea (containing $46 \% \mathrm{~N}$ ), $1.53 \mathrm{~g}$ of diamine phosphate (containing $12 \%$ $\mathrm{N}, 42 \% \mathrm{P}_{2} \mathrm{O}_{5}$ ), and $1.54 \mathrm{~g}$ of potassium sulphate (containing $52 \% \mathrm{~K}_{2} \mathrm{O}$ ) were applied as the base fertilizer and combined with the soil by mixing well.

There are two types of lettuce: leaf-expansion lettuce and heading lettuce. In the first season experiment, six-leaf and one-heart-stage lettuce was selected for colonization on 4 September 2020, with one plant per pot. The lettuce variety was leaf-expansion (Boston butter lettuce), the FC was $29.75 \%$ (volume percentage), and the soil bulk density was $1.21 \mathrm{~g} \cdot \mathrm{cm}^{-3}$. In the second season experiment, six-leaf and one-heart-stage lettuce was selected for colonization on 1 April 2021, with one plant per pot. The lettuce variety was heading lettuce (Italian Sagittarius 101 head lettuce), the FC was 31\% (volume percentage), and the soil bulk density was $1.36 \mathrm{~g} \cdot \mathrm{cm}^{-3}$.

\subsection{Experimental Design}

Four different water treatments were set up in the experiments as summarized in Table 1. The SWC was monitored by a soil moisture sensor. In this study, four different 
irrigation low limit treatments were carried out, with $100 \%$ as irrigation maximum and $90 \%$ (T1), 80\% (T2), 70\% (T3), and 60\% (T4) as irrigation low limit respectively. When the SWC decreased to the irrigation low limit, irrigation was performed to ensure that the SWC reaches the irrigation maximum. The irrigation quota was calculated in accordance with the national micro-irrigation technical standard [20]. The irrigation time and the amount of irrigation during the first and second seasons are illustrated in Figure 1. In the experiment, 52 pots were set for each planting season, of which 12 pots were placed on the scale, and 3 replicates were set for each treatment. The test arrangement is illustrated in Figure 2.

Table 1. Irrigation treatment design.

\begin{tabular}{cccccc}
\hline Treatment & Planting Season & T1 & T2 & T3 & T4 \\
\hline Irrigation & & \multicolumn{3}{c}{$100 \%$ FC } \\
maximums & & $90 \%$ FC & $80 \%$ FC & $70 \%$ FC & $60 \%$ FC \\
Irrigation minimums & & 116.21 & 112.04 & 109.35 & 105.16 \\
Irrigation & First season & 254.15 & 235.84 & 202.94 & 172.23 \\
amount/mm & Second season & & \\
\hline
\end{tabular}

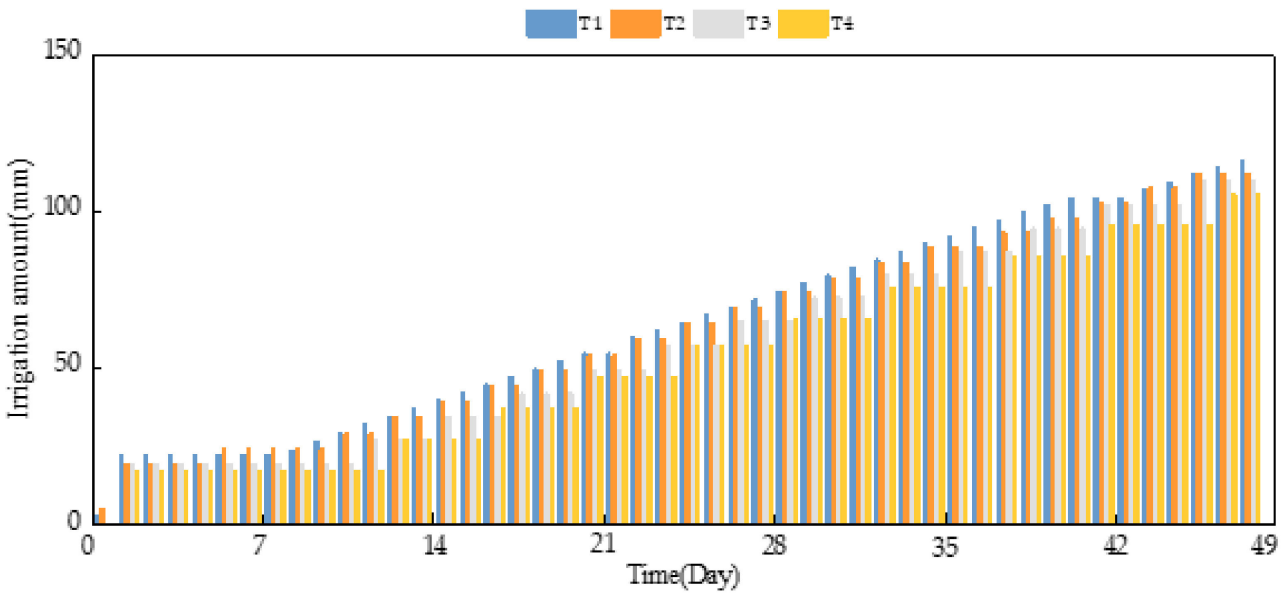

(a)

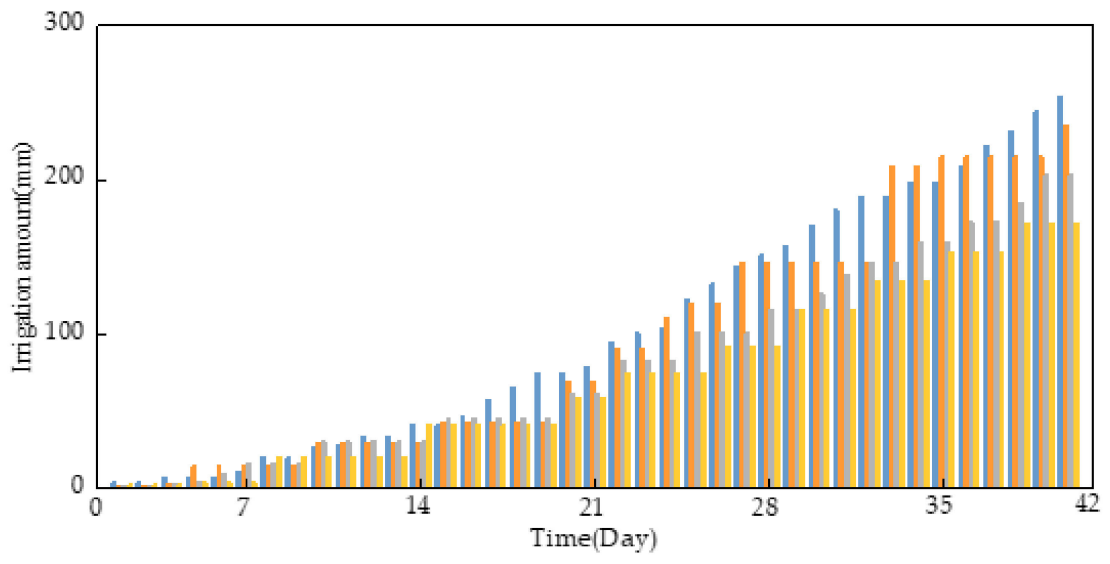

(b)

Figure 1. Irrigation amount and irrigation time (a) irrigation amount and irrigation time for planting lettuce in the first season, (b) irrigation amount and irrigation time for planting lettuce in the second season. 


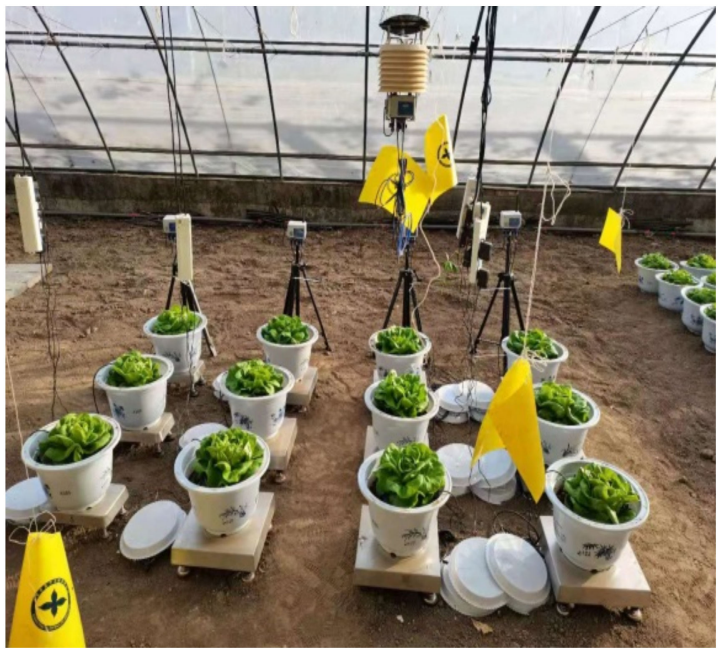

(a)

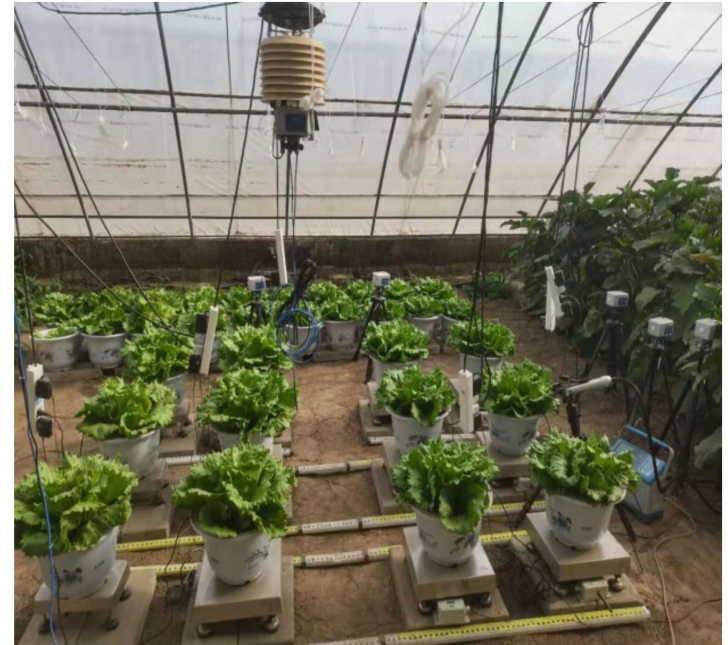

(b)

Figure 2. Test layout (a) first season, (b) second season.

\subsection{Measurement Items and Methods}

\subsubsection{SWC}

The first season experiment used the EC -5 soil moisture sensor produced by Decagon in the United States. The measurement accuracy is $\pm 1-2 \%$ SWC. The second season experiment used the TEROS12 soil moisture sensor produced by the US METER company. The resolution is $0.001 \mathrm{~m}^{3} / \mathrm{m}^{3}$, and the accuracy is $\pm 1-2 \%$ SWC. The sensor was inserted near the root of the lettuce, with the depth of the probe into the soil of $5.5 \mathrm{~cm}$. The change of SWC was monitored in real time and was collected automatically once every hour.

\subsubsection{Environmental Parameters}

The experiments used the greenhouse cloud environment EP400 data collector developed by the National Engineering Research Center for Intelligent Equipment in Agriculture for environmental monitoring. The data collector can detect air temperature (range: -40 to $80{ }^{\circ} \mathrm{C}$, accuracy: $\pm 0.5^{\circ} \mathrm{C}$ ), relative air humidity (range: $0-100 \%$, accuracy: $\pm 3 \%$ ), and light intensity (range: 0-100 klx, accuracy: $\pm 10 \mathrm{klx}$ ). Meteorological data were automatically collected hourly. The maximum and minimum air temperatures at the test site were recorded daily.

\subsubsection{Plant Parameters}

The CIRAS-3 photosynthetic apparatus produced by PP Systems was used to test the data from 9:00 to 17:00 on a sunny day. The second fully expanded leaf from top to bottom was selected to measure the transpiration rate and stomatal conductance of the leaves.

\subsection{4. $E T_{0}$}

The FAO-56 Penman-Monteith equation, based on microclimatology and energy balance, is the most practical and reliable method for calculating crop evapotranspiration. Satisfactory results have been obtained in experimental research of crop evapotranspiration infield and greenhouse. This greenhouse experiment uses the revised Penman-Monteith formula [21]. The calculation formula is as follows:

$$
E T_{0}=\frac{0.408 \Delta\left(R_{\mathrm{n}}-G\right)+\gamma \frac{1713\left(\mathrm{e}_{s}-e_{a}\right)}{T+273}}{\Delta+1.64 \gamma}
$$

where $E T_{0}$ represents the reference crop evapotranspiration $(\mathrm{mm} / \mathrm{d}) ; R_{\mathrm{n}}$ is net radiation of the crop canopy $\left(\mathrm{MJ} /\left(\mathrm{m}^{2} \mathrm{~d}\right)\right)$; $\mathrm{G}$ is the soil heat flux density $\left(\mathrm{MJ} /\left(\mathrm{m}^{2} \mathrm{~d}\right)\right)$; $\mathrm{T}$ is the daily 
average temperature at a height of $1.5-2.5 \mathrm{~m}$ above the ground $\left({ }^{\circ} \mathrm{C}\right) ; e_{\mathrm{S}}$ is the average saturated vapor pressure at $1.5-2.5 \mathrm{~m}$ above the ground $(\mathrm{kPa}) ; e_{\mathrm{a}}$ is the average actual vapor pressure at a height of $1.5-2.5 \mathrm{~m}$ above the ground $(\mathrm{kPa}) ; \Delta$ is the slope of the saturated vapor pressure curve $\left(\mathrm{kPa} /{ }^{\circ} \mathrm{C}\right)$, and $\gamma$ is the wet and dry constants of values, $0.067 \mathrm{kPa} /{ }^{\circ} \mathrm{C}$.

\subsection{5. $K_{c}$}

$K_{\mathrm{c}}$ refers to the ratio of the actual water consumption during the growth stage to the reference crop evapotranspiration. The calculation formula is as follows:

$$
K_{\mathrm{c}}=\frac{E T_{\mathrm{c}}}{E T_{0}}
$$

where $K_{\mathrm{c}}$ is the crop coefficient, $E T_{0}$ is the reference crop evapotranspiration during the growth period of the crop $(\mathrm{mm} / \mathrm{d})$, and $E T_{\mathcal{C}}$ is the water consumption at the crop stage during the growth period of the crop $(\mathrm{mm} / \mathrm{d})$.

\subsubsection{Saturated Water Vapor Pressure Deficit (VPD)}

$V P D$ is the difference between the saturated water vapor pressure of the ambient air and the actual water vapor pressure, which affects the closure of the crop stomata. It is commonly used to evaluate atmospheric water demand. Its calculation formula is as follows:

$$
V P D=0.611 \times e^{\frac{12.27 T_{a}}{237.3+T_{a}}} \times\left(1-\frac{R H}{100}\right)
$$

where $V P D$ is the saturated vapor pressure of the air $(\mathrm{kPa}), T_{a}$ is the atmospheric temperature $\left({ }^{\circ} \mathrm{C}\right)$, and $R H$ is the relative humidity of the air $(\%)$.

\subsection{Pearson Correlation}

Pearson correlation coefficient is often used to detect whether the independent and dependent variables are correlated. The value ranges from -1 to 1 , and the formula is as follows:

$$
P_{\mathrm{xy}}=\frac{\sum(x-\bar{x})(y-\bar{y})}{\sqrt{\sum(x-\bar{x})^{2} \sum(y-\bar{y})^{2}}}
$$

where, $\sum(x-\bar{x})(y-\bar{y})$ is the covariance between variable $x$ and variable $y, \sum(x-\bar{x})^{2} \sum(y-\bar{y})^{2}$ is the standard deviation between variable $x$ and variable $y, P_{x y}$ is the correlation coefficient. The greater the absolute value of the correlation coefficient, the stronger the correlation. The closer the correlation coefficient is to 1 or -1 , the stronger the correlation is; the closer the correlation coefficient is to 0 , the weaker the correlation is Ref. [22].

\subsection{Parameter Calculation Module of IWS}

The IWS can continuously monitor plants online in real time. According to the changes of weight $\left(\mathrm{W}_{\mathrm{IWS}}\right)$, the IWS can analyze the daily evapotranspiration $(E T)$, weight gain change $\left(\triangle P W_{n}\right)$, instantaneous whole plant transpiration rate $(E)$, and stomatal conductance $\left(g_{s c}\right)$ of plants $[23,24]$.

$$
E T_{C}=W_{m}-W_{e}
$$

where $E T_{\mathcal{C}}$ is the difference between the readings of the IWS at 00:00 of the present day and that at 00:00 of the next day $(\mathrm{g}), W_{m}$ is the average weight of the two sampling moments before and after 00:00 of the day $(\mathrm{g}), W_{e}$ is the average weight of the two sampling moments before and after 00:00 the next day $(\mathrm{g})$.

$$
\Delta P W_{n}=W_{n}-W_{n-1}
$$

where $\triangle P W_{n}$ can be calculated by the difference of the weight between the $n$th irrigation and the $n-1$ th irrigation $(\mathrm{g}), W_{n}$ is the average weight of the two sampling times before 
and after the nth irrigation $(\mathrm{g}), W_{n-1}$ is the average weight of the two sampling times before and after the $n-1$ th irrigation $(\mathrm{g})$.

$$
E=-\left(\frac{d W}{d t}\right)_{k} \approx-\frac{W_{k}-W_{k-1}}{t_{k}-t_{k-1}}
$$

where $E$ is obtained by multiplying the first derivative of the measured time series by $-1\left(\mathrm{~g} \mathrm{~h}^{-1}\right), W_{k}$ is the IWS reading when time is $t_{k}(\mathrm{~g}), W_{k-1}$ is the IWS reading when the time is $t_{k-1}(\mathrm{~g})$. The weight gain of the plant in the short time interval, which is used to calculate the transpiration rate, is assumed to be negligible. Under the condition of soil water deficit, the WUE of the plant changes very little. Hence, it can be neglected.

$$
g_{s c}=\frac{E \cdot P_{a t m}}{L A \cdot V P D}
$$

where $g_{s c}$ is calculated as the ratio of the transpiration rate of the entire plant, the atmospheric pressure to the leaf surface area and the saturated vapor pressure deficit ( $\mathrm{mmol}$ $\left.\mathrm{m}^{-2} \mathrm{~s}^{-1}\right), P_{\text {atm }}$ is the atmospheric pressure $(101.3 \mathrm{kPa}), E$ is the transpiration rate $\left(\mathrm{g} \mathrm{h}^{-1}\right)$, $L A$ is the leaf surface area $\left(\mathrm{m}^{2}\right), V P D$ is the saturated water vapor pressure deficit $(\mathrm{KPa})$.

\subsection{Data Analysis}

Data analysis was performed by SPSS software, chart drawings were created by Origin software, data processing was conducted by Excel software, and significance analysis was conducted by performing one-way analysis of variance.

\subsection{Technical Roadmap}

The experimental technical roadmap is illustrated in Figure 3, which includes the following steps: 1 . With lettuce as the research object and IWS as the tool, the weight of potted lettuce ( $\mathrm{W}_{\text {IWS }}$ ) is measured according to the IWS; 2 . According to $\mathrm{W}_{\text {IWS}}$, the characteristic parameters of soil (soil moisture weight [SW]), plant ([$\left.\left.\Delta P W_{n}\right],\left[g_{s c}\right],[E]\right)$, and atmosphere $\left(E T_{c}\right)$ are analyzed. $K_{\mathrm{c}}$ is calculated from $E T_{c}$ and $E T_{0} ; 3$. The optimal irrigation model is obtained by comparing irrigation water use efficiency (IWUE), WUE, and yield.

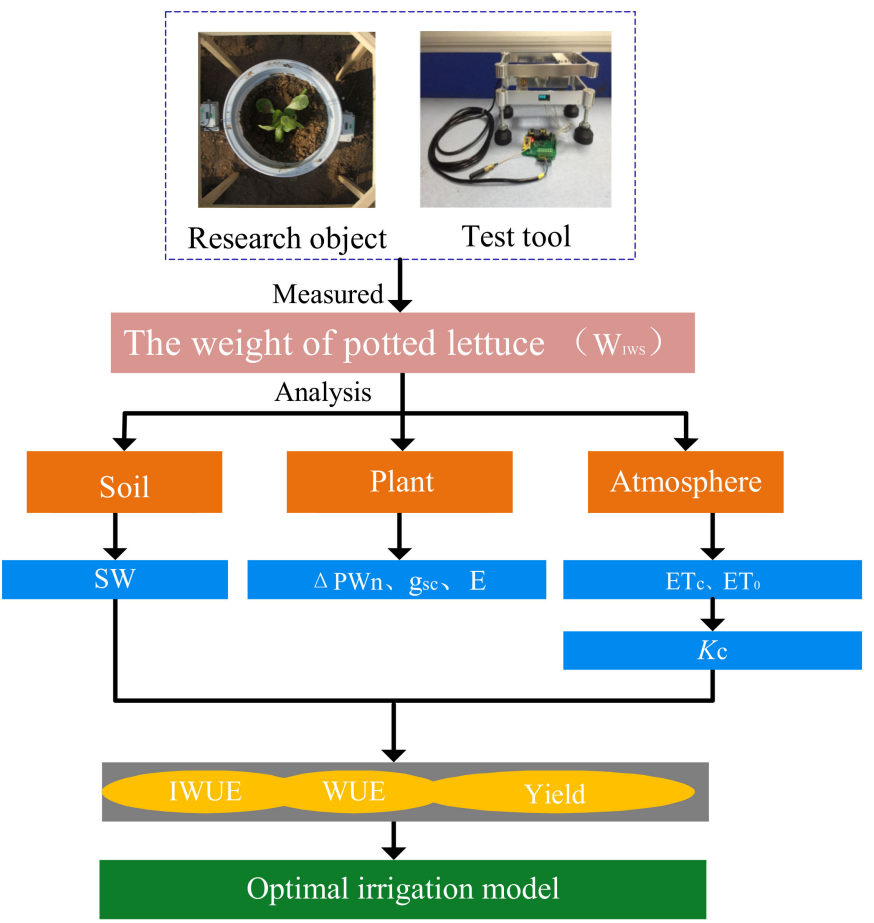

Figure 3. Technology roadmap. 


\section{Results}

\subsection{Hardware Design Module of IWS}

Figure 4 illustrates the hardware structure of the IWS developed by Beijing Research Center for Intelligent Equipment in Agriculture. It includes six parts: the main controller, power supply, data collection, data display, data storage, and communication module. The main controller uses STM32's low-power series L431CCT6, which can coordinate the normal operation of various components. The power supply uses TI's TPS61221 boost chip to convert the $3 \mathrm{~V}$ voltage provided by the dry battery to an operating voltage of $3.3 \mathrm{~V}$ required by the system. For data collection, the HX712 electronic scale-dedicated high-precision A/D conversion chip from Haixin Technology Co., Shenzhen, China is used to collect the weight information. The data display adopts a 0.91 inch OLED with an SSD1306 controller, which can display the real-time weight and time of the scale. Data storage uses NOR flash type W25Q64, which is used to store system parameters and backup the real-time weight and time of the collection scale. The communication module adopts low-power wide-area network technology for data transmission between nodes and industrial tablet computers [17].

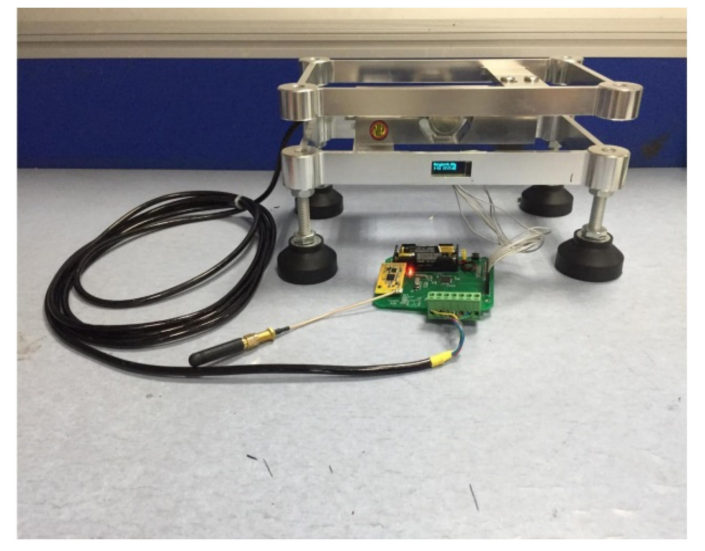

Figure 4. Hardware structure diagram of IWS.

\subsection{Analysis of the Changes of Soil Moisture Content under Different Water Treatments Based on IWS}

Figure 5a illustrates the change trend of the relative weight of the IWS during the entire growth period under different water treatments (RW is the ratio of the weight at different weighing times to the weight at the beginning). The IWS can accurately reflect the changes in the weight of potted plants at different times during different growth periods. The direction of the arrow indicates the time of irrigation, and the increase in the dotted line indicates an increase in plant weight. With the change of the irrigation amount, RW fluctuates. The fluctuation range of soil moisture under T1 treatment is significantly smaller than that of the other treatments. This is because the single irrigation amount of T1 treatment is small. As the growth period progresses, the frequency of irrigation gradually increases. In the early stage of seedlings, lettuce is not processed because of soil moisture irrigation. During the rosette stage, the leaf area of lettuce increases, the water consumption increases as well, and the peak moments are different under different water treatments. At the end of heading, the lettuce is close to maturity, the water demand decreases, and the frequency of changes in RW decreases as well. During the entire growth period, in the first season experiment, the RW intervals of T1, T2, T3, and T4 are 0.95-1.08, 0.94-1.06, 0.93-1.06, and $0.92-1.05$, respectively. The RW ranges of T1, T2, T3, and T4 in the second season are $0.90-1.14,0.89-1.14,0.89-1.11$, and 0.89-1.10, respectively. 


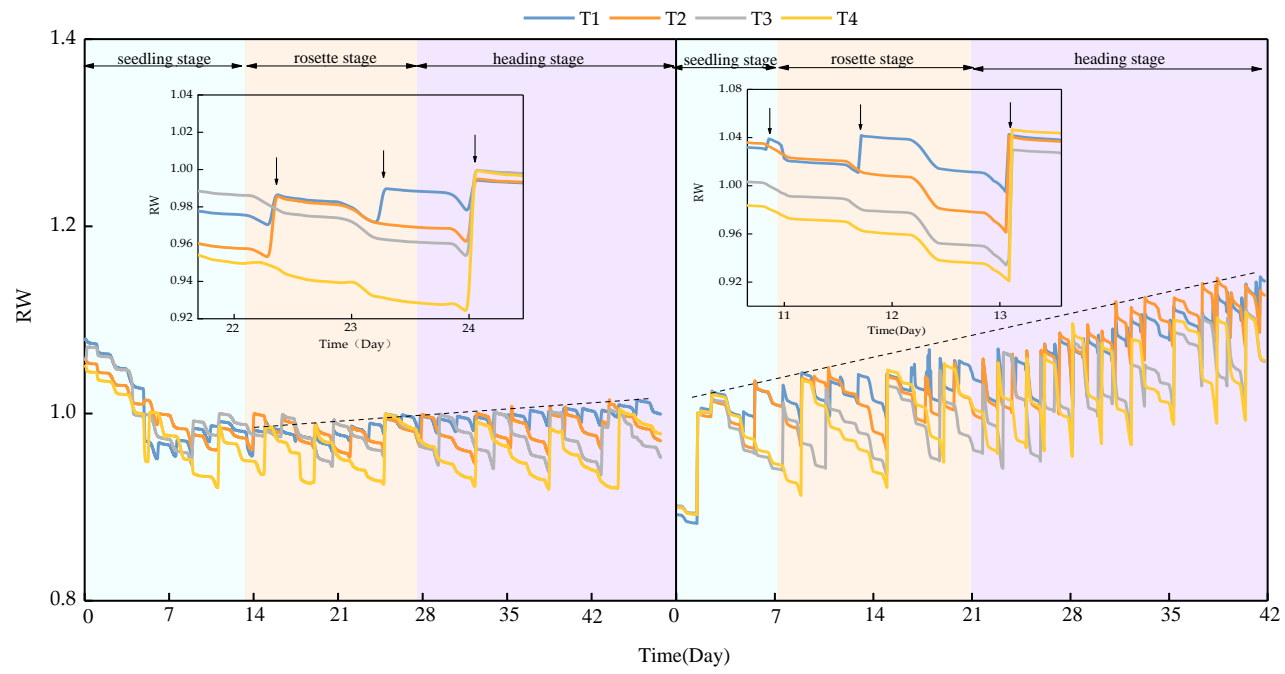

(a)

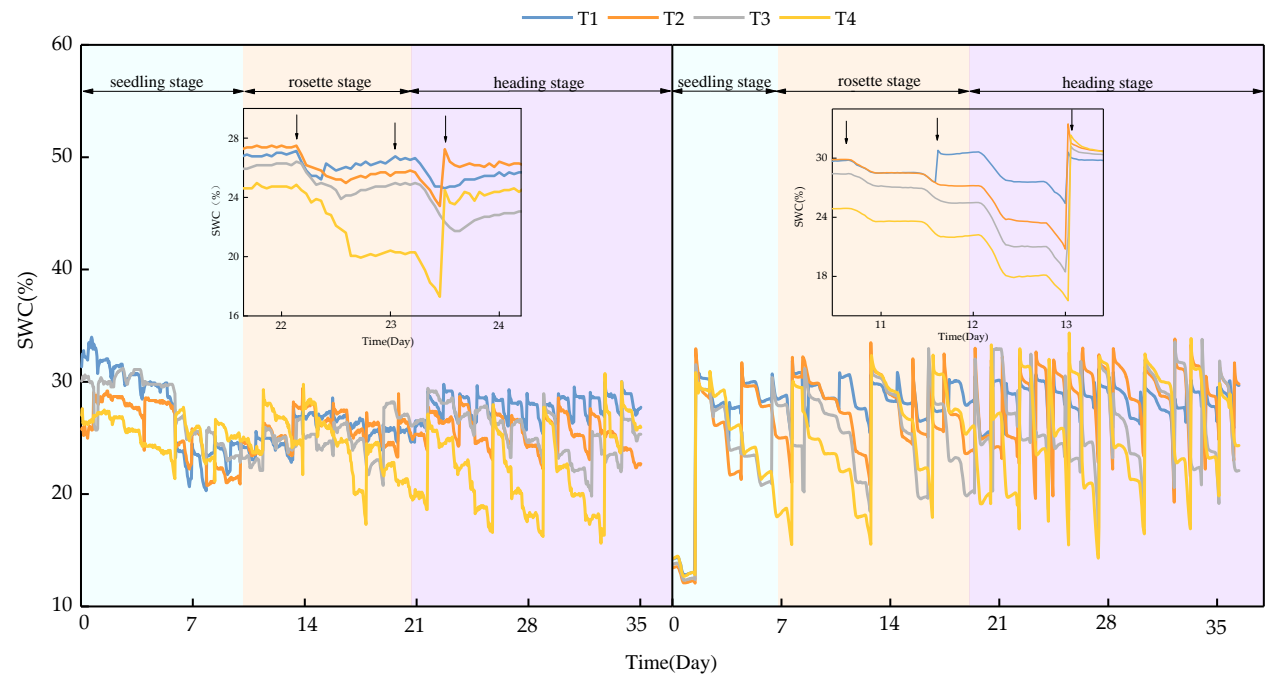

(b)

Figure 5. Changes of RW and SWC under different water treatments (a) RW change of lettuce in the first and second seasons under different water treatments, (b) SWC change under different water treatments in the first and second seasons.

Figure $5 \mathrm{~b}$ illustrates the change trend of SWC during the entire growth period under different water treatments. The SWC of lettuce fluctuates under different water treatments. In the first season, the upper limit of SWC for T1, T2, T3, and T4 is $29.75 \%$, and the irrigation low limit is $26.77 \%, 23.80 \%, 20.82 \%$, and $17.85 \%$, respectively. In the second season, the upper limit of SWC for T1, T2, T3, and T4 is $31.00 \%$, and the irrigation low limit is $27.90 \%$, $24.80 \%, 21.70 \%$, and $18.60 \%$, respectively. When the SWC of T1, T2, T3, and T4 drops to the corresponding lower limit, the irrigation will be performed until the SWC reaches the irrigation maximum. The figure illustrates that the first season experiment belongs to the autumn stubble. As the temperature decreases, the water consumption of lettuce decreases, and the frequency of SWC fluctuations gradually decreases as well. The second season test is spring stubble. As the temperature increases, the water consumption of lettuce increases, and the frequency of SWC fluctuations gradually increases as well. The average soil moisture content is the lowest under T4 treatment and is in a long-term low-moisture state.

The IWS is more consistent with the change trend of the SWC. The maximum and minimum values of SWC correspond to the moments when the maximum and minimum 
values of $\mathrm{W}_{\text {IWS }}$ appear, which indicates that the IWS can sensitively describe the influence of soil moisture changes.

Linear regression analysis is used to fit the $\mathrm{W}_{\text {IWS }}$ and $\mathrm{SW}$ of four irrigation low limit treatments to further explore the accuracy of $W_{\text {IWS }}$ response to $S W$ under different water treatments. As illustrated in Figure 6, the fitting effect of $W_{\text {IWS }}$ and its corresponding SW under the four gradients in the first and second seasons is quite good, reaching a significant level of $5 \%$. The determination coefficients for the first and second seasons are $0.87,0.87$, $0.94,0.85$, and $0.64,0.73,0.70,0.76$, respectively (Table 2). Overall, because the weight of the lettuce in the second season is more than three times of that in the first season, the weight symmetry of the lettuce has a higher influence. For a similar water weight in the soil, the weight of the scale varies widely. Therefore, the coefficient of determination in the second season is lower than that in the first season.

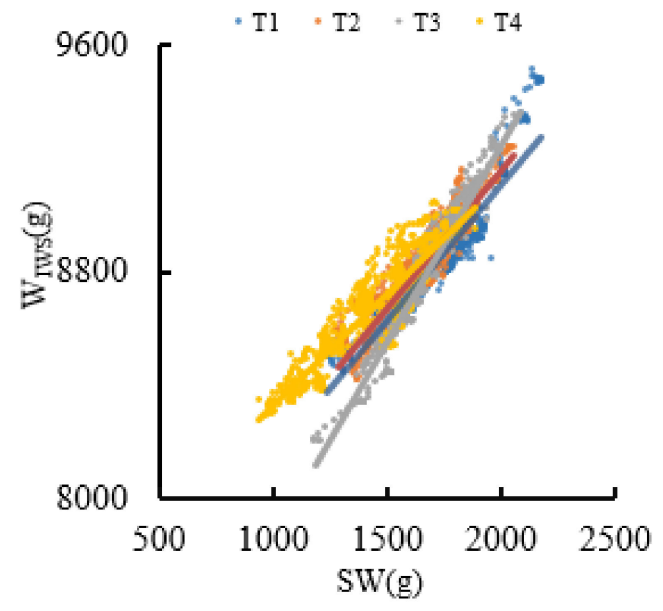

(a)

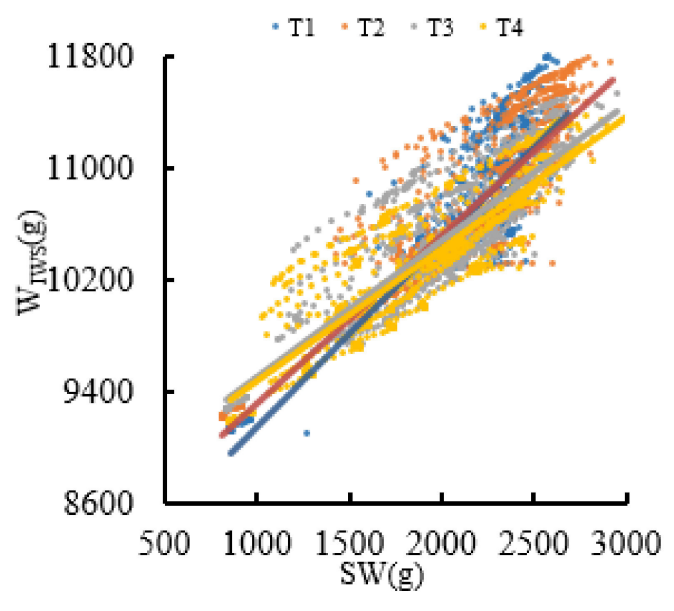

(b)

Figure 6. The fitting of SW and $\mathrm{W}_{\text {IWS }}$ under different water treatments. (a) First season, (b) second season.

Table 2. Regression analysis of SW and $\mathrm{W}_{\text {IWS }}$ under different water treatments.

\begin{tabular}{ccccc}
\hline Planting Season & Treatment & Fitted Equation & Determination Coefficient $/ \mathbf{R}^{2}$ & $p$ \\
\hline \multirow{5}{*}{ First season } & T1 & $\mathrm{W}_{\text {IWS }}=0.96 \mathrm{SW}+7186.5$ & 0.87 & $* *$ \\
& $\mathrm{~T} 2$ & $\mathrm{~W}_{\text {IWS }}=0.96 \mathrm{SW}+7226.4$ & 0.87 & $* *$ \\
& $\mathrm{~T} 3$ & $\mathrm{~W}_{\text {IWS }}=1.39 \mathrm{SW}+6472.0$ & 0.94 & $* *$ \\
& $\mathrm{~T} 4$ & $\mathrm{~W}_{\text {IWS }}=0.79 \mathrm{SW}+7541.2$ & 0.85 & $* *$ \\
Second season & $\mathrm{T} 1$ & $\mathrm{~W}_{\text {IWS }}=1.33 \mathrm{SW}+7830.1$ & 0.64 & $*$ \\
& $\mathrm{~T} 2$ & $\mathrm{~W}_{\text {IWS }}=1.21 \mathrm{SW}+8094.3$ & 0.73 & $*$ \\
& $\mathrm{~T} 3$ & $\mathrm{~W}_{\text {IWS }}=0.97 \mathrm{SW}+8525.9$ & 0.70 & $*$ \\
\hline
\end{tabular}

Note: ** means the difference between the two variables is extremely significant.

\subsection{Growth Analysis under Different Water Treatments Based on IWS}

Figure 7 illustrates the change trend of lettuce weight gains under different water treatments. According to the IWS, $\triangle P W_{n}$ and cumulative weight gain $\left(\Sigma P W_{n}\right)$ of lettuce are calculated, which can clearly reflect the growth of lettuce in different growth periods, and describe the weight change of lettuce throughout the growth cycle. The figure indicates that $\triangle P W_{n}$ generally increases first and then gradually decreases. Under different water treatments, the weight gain rates of T1, T2, T3, and T4 in the first season are $7.37 \mathrm{~g} / \mathrm{d}$, $8.27 \mathrm{~g} / \mathrm{d}, 7.80 \mathrm{~g} / \mathrm{d}$ and $7.08 \mathrm{~g} / \mathrm{d}$, respectively. The weight gain rates of T1, T2, T3, and T4 in the second season are $29.75 \mathrm{~g} / \mathrm{d}, 33.03 \mathrm{~g} / \mathrm{d}, 22.99 \mathrm{~g} / \mathrm{d}$, and $20.26 \mathrm{~g} / \mathrm{d}$, respectively. In the first season, the $\triangle P W_{n}$ of the lettuce under the T2 treatment is the highest in the seedling and rosette stages, and the $\triangle P W_{n}$ of the lettuce under the T3 treatment is the highest in 
the late heading stage. During each growth period of lettuce in the second season, $\Delta P W_{n}$ is the highest under T2 treatment. Overall, lettuce has the fastest weight gain rate under T2 treatment, and $\triangle P W_{n}$ is the highest. At the end of the growth period, the $\Sigma P W_{n}$ of T1, $\mathrm{T} 2$, T3, and T4 in the first season is $361 \mathrm{~g}, 405 \mathrm{~g}, 382 \mathrm{~g}$, and $347 \mathrm{~g}$, respectively. The $\Sigma P W_{n}$ of T1, T2, T3, and T4 in the second season is $1239.67 \mathrm{~g}, 1417.34 \mathrm{~g}, 965.87 \mathrm{~g}$, and $851.167 \mathrm{~g}$ respectively. At the 5\% significance level, the differences between the different treatments are significant.

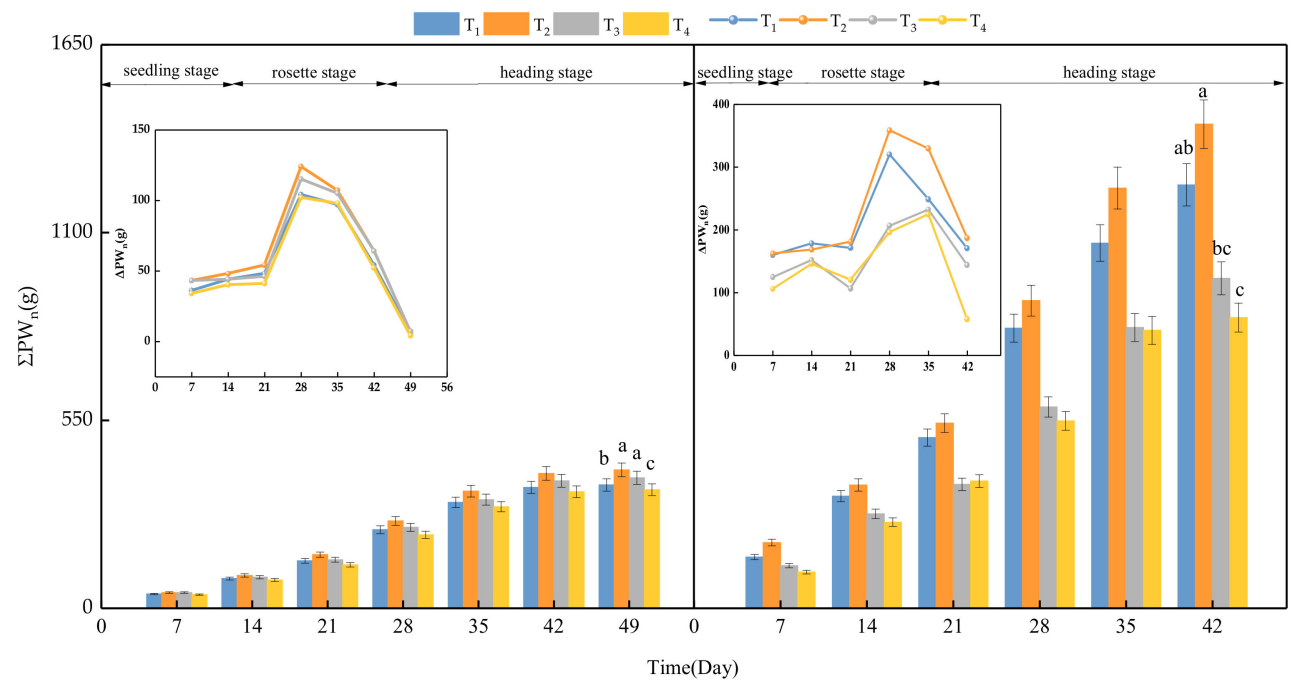

Figure 7. Changes of lettuce weight under different water treatments. Note: The bars with different letters showed significant difference $(\alpha=0.05)$. The same as below.

Null hypothesis means that there is no significant difference in the mean values of the controlled variables observed at different levels, that is, there is no significant difference in the mean values of experimental results under four different water treatments. Partial results of one-way ANOVA are shown in Table 3. The significance of lettuce weight gain in the first season is 0.00 and 0.02 in the second season. Both are less than 0.05 . At the significance level of 0.05 , the probability value $p$ is lower than 0.05 , so the null hypothesis is not valid. It is believed that if the overall mean values of the observed variables are different at different levels, then the different water treatments have significant effects on the weight gain of lettuce.

Table 3. Analysis of univariate variance for different water treatments.

\begin{tabular}{|c|c|c|c|c|c|c|}
\hline Planting Season & & Quadratic Sum & Degree of Freedom & Mean Square & $\mathbf{F}$ & Significant \\
\hline \multirow{3}{*}{ First Season } & Among groups & 6500.92 & 3 & 2166.97 & 46.60 & 0.00 \\
\hline & Group communication & 372.00 & 8 & 46.50 & & \\
\hline & Gross & 6872.92 & 11 & & & \\
\hline \multirow{3}{*}{ Second season } & Among groups & $556,997.08$ & 3 & $185,665.69$ & 6.574 & 0.02 \\
\hline & Group communication & $225,944.99$ & 8 & $28,243.12$ & & \\
\hline & Gross & $782,942.07$ & 11 & & & \\
\hline
\end{tabular}

\subsection{Physiological Analysis under Different Water Treatments Based on IWS}

Figure 8 illustrates the $E$ of the whole lettuce during the entire growth period under different water treatments. To eliminate the influence of lettuce size on E, we normalize it to the leaf surface area. The figure illustrates that during the entire growth period, $E$ exhibits a significant fluctuating change. As the growth period progresses, lettuce $E$ gradually decreases. Under different water treatments, the hourly average $E$ during the entire growth period of T1, T2, T3, and T4 in the first season is $2.43 \mathrm{~g} \cdot \mathrm{h}^{-1}, 2.57 \mathrm{~g} \cdot \mathrm{h}^{-1}, 2.35 \mathrm{~g} \cdot \mathrm{h}^{-1}$ and $2.02 \mathrm{~g} \cdot \mathrm{h}^{-1}$. The average hourly $E$ during the entire growth period of T1, T2, T3 and T4 in 
the second season is $2.23 \mathrm{~g} \cdot \mathrm{h}^{-1}, 2.29 \mathrm{~g} \cdot \mathrm{h}^{-1}, 2.22 \mathrm{~g} \cdot \mathrm{h}^{-1}$, and $2.12 \mathrm{~g} \cdot \mathrm{h}^{-1}$, respectively. The research results in the first and second seasons indicate that $E$ is at its lowest value for a long time under T4 treatment. At the 5\% significance level, the differences between the different water treatments are significant.

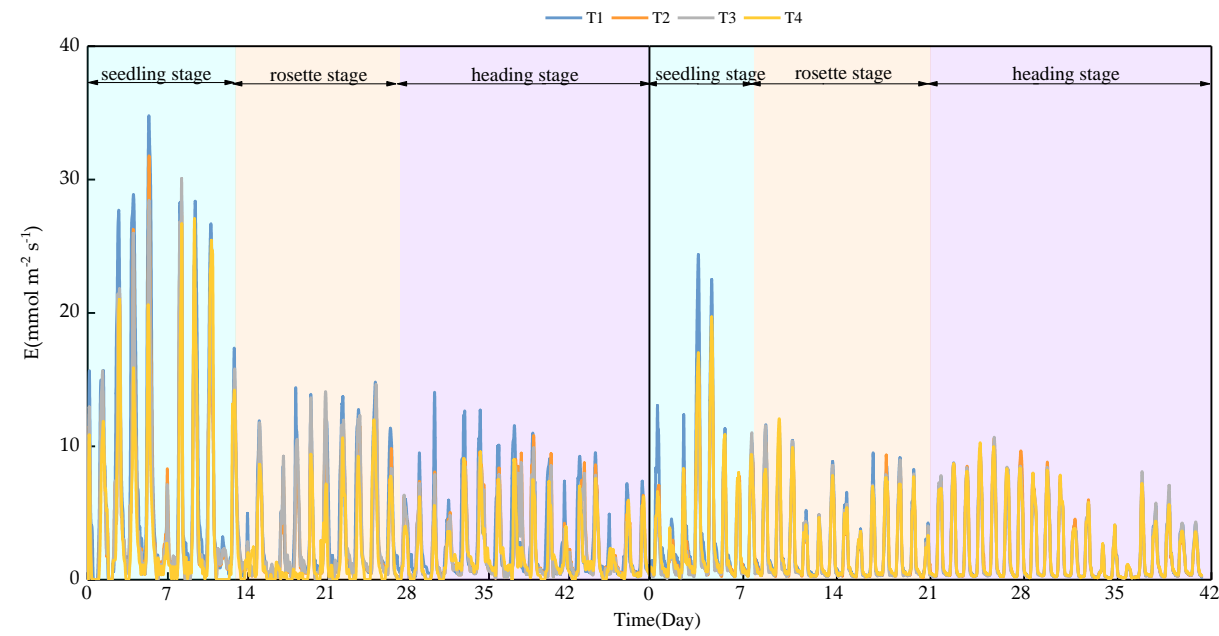

Figure 8. E changes under different water treatments.

$g_{s c}$ is the main channel for gas exchange between plant leaves and the outside world, and the degree of stomatal dispersion has a direct effect on transpiration. Figure 9 illustrates the change trend of the $g_{s c}$ of lettuce under different water treatments. Generally, the $g_{s c}$ of lettuce decreases gradually, and $g_{s c}$ decreases significantly in the late seedling stage. Under different water treatments, the average hourly $g_{s c}$ of T1, T2, T3, and T4 in the first season are $364.53 \mathrm{mmol} \mathrm{m} \mathrm{m}^{-2} \mathrm{~s}^{-1}, 396.48 \mathrm{mmol} \mathrm{m}^{-2} \mathrm{~s}^{-1}, 326.48 \mathrm{mmol} \mathrm{m}^{-2} \mathrm{~s}^{-1}$, and $300.60 \mathrm{mmol} \mathrm{m}^{-2} \mathrm{~s}^{-1}$, respectively. The average hourly $g_{s c}$ of T1, T2, T3, and T4 in the second season are $180.32 \mathrm{mmol} \mathrm{m}^{-2} \mathrm{~s}^{-1}, 186.85 \mathrm{mmol} \mathrm{m}^{-2} \mathrm{~s}^{-1}, 172.07 \mathrm{mmol} \mathrm{m}^{-2} \mathrm{~s}^{-1}$, and $162.74 \mathrm{mmol} \mathrm{m}^{-2} \mathrm{~s}^{-1}$, respectively. When the plant is in the seedling stage, a major difference in $g_{s c}$ exists under different water treatments. As time progresses, the difference gradually decreases. The $g_{s c}$ values of the first and second seasons are considerably different. This is because although the $\mathrm{ET}_{\mathrm{C}}$ of lettuce in the second season is higher than that in the first season, the $g_{s c}$ normalized leaf area in the second season is more than three times that in the first season; hence, the $g_{s c}$ in the second season is lower than that in the first season. At the 5\% significance level, significant differences exist between the different water treatments.

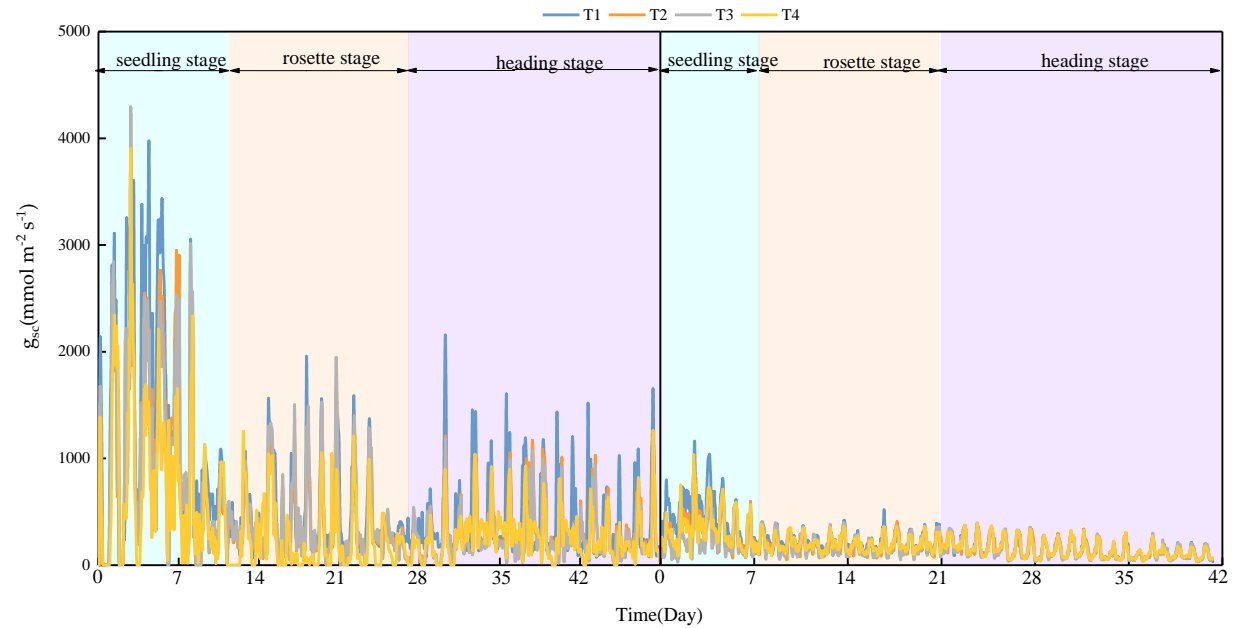

Figure 9. $g_{s c}$ changes under different water treatments. 
In addition, we simultaneously measured the $E$ and $g_{s c}$ of lettuce leaves under the four moisture gradients on the IWS using a photosynthesis meter. Figure 10 illustrates the actual measured value of lettuce by a photosynthetic instrument in the second season and the experimental value calculated according to the IWS. The accuracy of the measurements is hence verified.

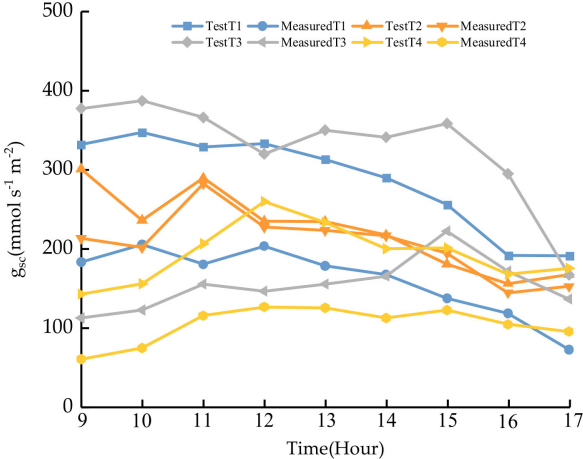

(a)

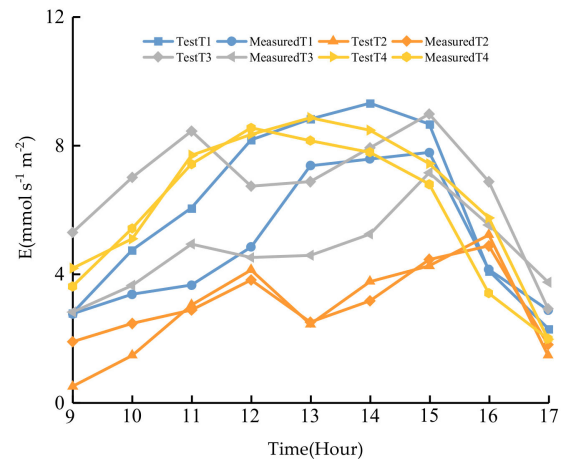

(b)

Figure 10. Changes of photosynthetic parameters of lettuce leaves in one day under different water treatments; (a) measured value and test value of E; (b) measured and experimental values of $g_{s c}$.

\subsection{Plant Evapotranspiration Analysis under Different Water Treatments Based on IWS}

Based on the $E T_{0}$ calculated according to the weather monitoring data (Figure 11a), the $E T_{0}$ in the first season generally indicates a fluctuating downward trend owing to daily temperature changes during the entire growth period. $E T_{0}$ reaches the highest level in the seedling stage, which is $2.76 \mathrm{~mm} \mathrm{~d}^{-1} . E T_{0}$ reaches the lowest value in the heading stage, which is $0.80 \mathrm{~mm} \mathrm{~d}^{-1}$. The $E T_{0}$ of the second season generally indicates a volatile upward trend. $E T_{0}$ reaches its highest value during the heading stage, which is $4.22 \mathrm{~mm} \mathrm{~d}^{-1} . E T_{0}$ reaches the lowest level in the seedling stage, which is $2.99 \mathrm{~mm} \mathrm{~d}^{-1}$. Figure $11 \mathrm{~b}$ illustrates that the $E T_{c}$ of lettuce calculated according to the IWS can clearly show the water demand of lettuce at different growth periods, and describe the water consumption characteristics of plants throughout the growth cycle. During the entire growth period, the $E T_{c}$ fluctuates up and down. The $E T_{c}$ of lettuce is the highest under T2 treatment. The $E T_{c}$ of lettuce in the first season is $112.52 \mathrm{~mm} \mathrm{~d}^{-1}$, which is $2.70 \%, 2.35 \%$, and $5.21 \%$ higher than that under other treatments. The $E T_{c}$ of lettuce in the second season is $278.61 \mathrm{~mm} \mathrm{~d}^{-1}$, which is $32.07 \%, 23.21 \%$, and $31.05 \%$ higher than that under other treatments. The $E T_{c}$ of lettuce in the second season is different from that in the first season. Although the temperature in the greenhouse in the second season is higher than that in the first season, the leaf area of lettuce in the second season is larger than that in the first season, and transpiration and photosynthesis are stronger, which leads to an increase in the water demand. Judging from the overall changes in the first and second seasons, the trends of $E T_{\mathcal{c}}$ and $E T_{0}$ are roughly similar.

Based on the $E T_{c}$ calculated by IWS, and $E T_{0}$ calculated by the modified PenmanMonteith formula, the daily $K_{\mathrm{c}}$ can be calculated as well. This reflects the $K_{\mathrm{c}}$ changes of crops at different stages in real time. Figure 12 illustrates that the lettuce $K_{\mathrm{c}}$ is different in different growth periods, and $K_{\mathrm{c}}$ indicates a gradual increasing trend. Under different water treatments, the daily average $K_{\mathrm{c}}$ of lettuce under T1, T2, T3, and T4 treatments in the first season are $1.64,1.68,1.67$, and 1.57 , respectively. The daily average $K_{\mathrm{c}}$ of lettuce under $\mathrm{T} 1, \mathrm{~T} 2, \mathrm{~T} 3$, and $\mathrm{T} 4$ treatments in the second season are $1.38,1.81,1.47$, and 1.38 , respectively. Combined with the results of the first and second seasons, it can be seen that as the growth period advances, the $K_{c}$ of lettuce in the heading stage reaches the highest value, which is 2.26 and 2.56 , respectively. 


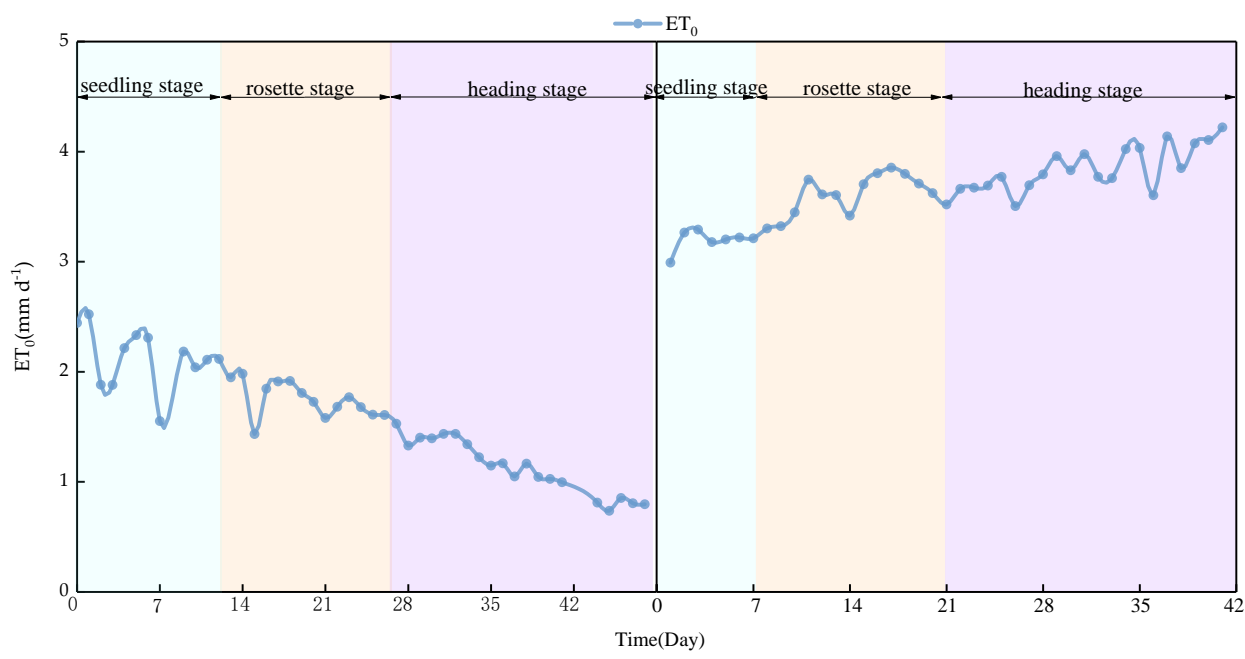

(a)

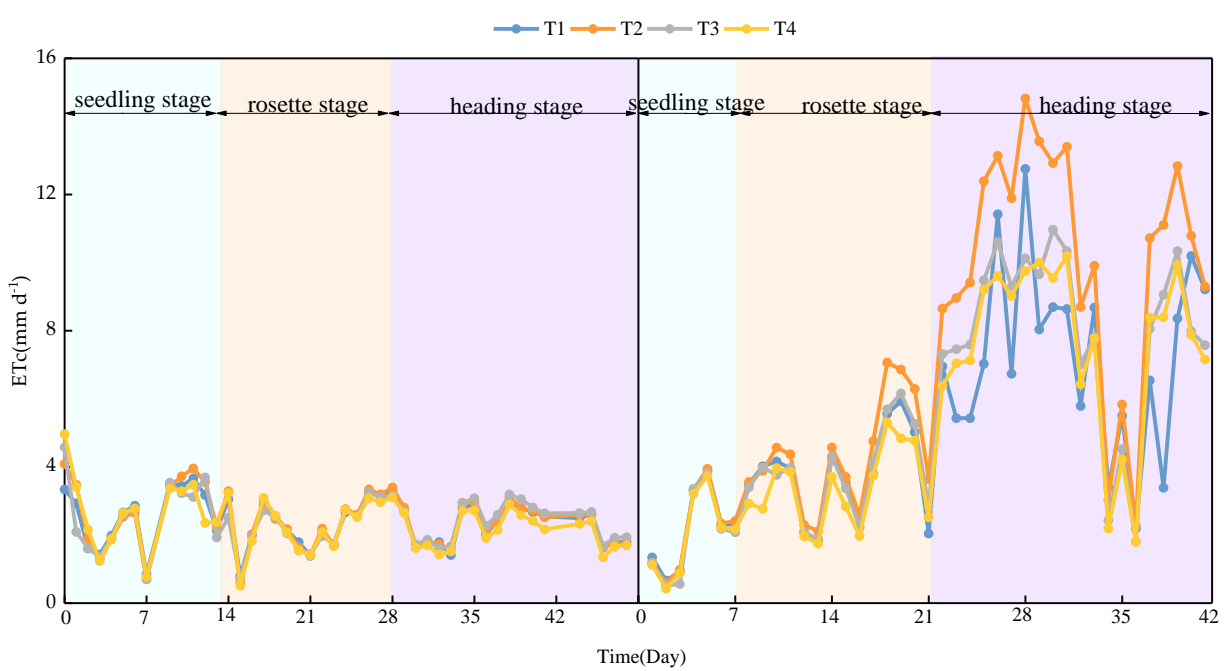

(b)

Figure 11. $E T_{0}$ and $E T_{\mathcal{C}}$ changes under different water treatments (a) $E T_{0}$, (b) $E T_{\mathrm{c}}$.

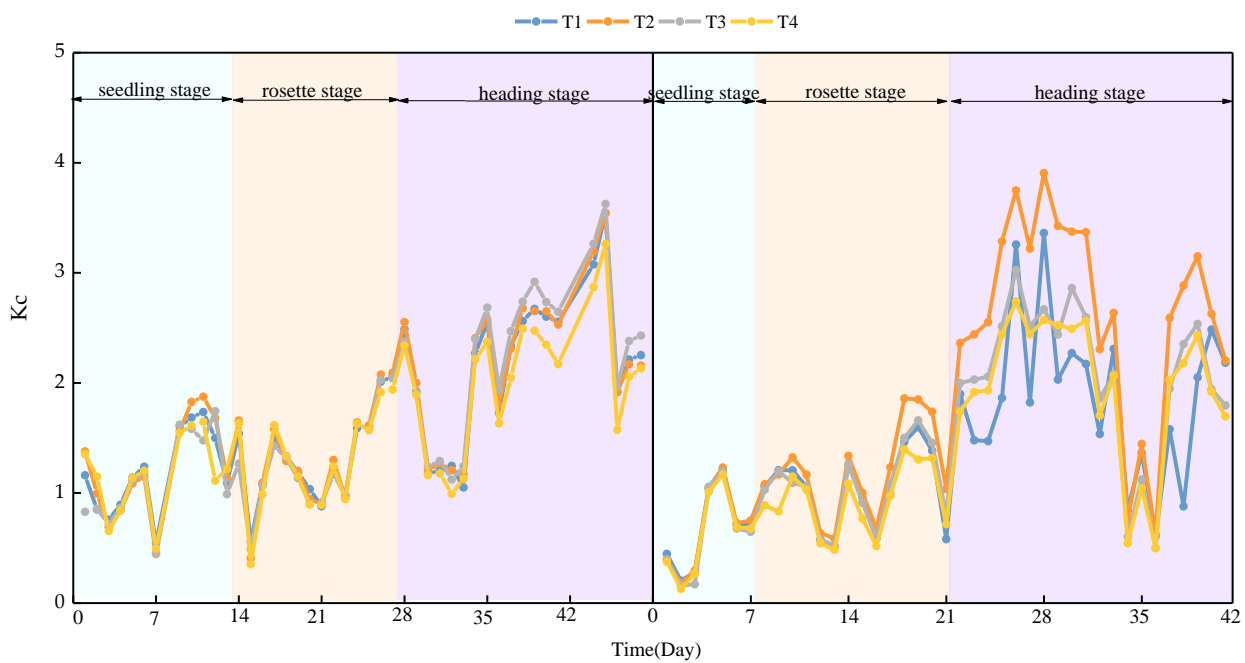

Figure 12. $K_{\mathrm{c}}$ changes under different water treatments. 
Table 4 indicates that the $K_{\mathrm{c}}$ of lettuce gradually increases during the entire growth period. The water consumption of lettuce varies significantly in different growth stages, and the water consumption modulus gradually increases as the growth period progresses. The test results of the first and second seasons indicate that the water consumption modulus during the heading stage is the highest. The first season accounts for approximately $48 \%$ of the total water consumption, and the second season accounts for approximately $70 \%$ of the total water consumption. It shows that the water consumption of lettuce increases during the heading stage. As the growth period progresses, the difference under different water treatments gradually increases. Overall, $K_{c}$ under T4 treatment is the lowest. In the first season, $K_{\mathrm{c}}$ decreases by $7.96 \%, 8.64 \%$, and $12.44 \%$ under T1, T2, and T3 treatments, respectively. In the second season, $K_{\mathrm{c}}$ decreases by $19.29 \%, 34.52 \%$, and $5.08 \%$ under $\mathrm{T} 1, \mathrm{~T} 2$, and $\mathrm{T} 3$ treatments, respectively.

Table $4 . K_{\mathrm{c}}$ and water consumption of lettuce.

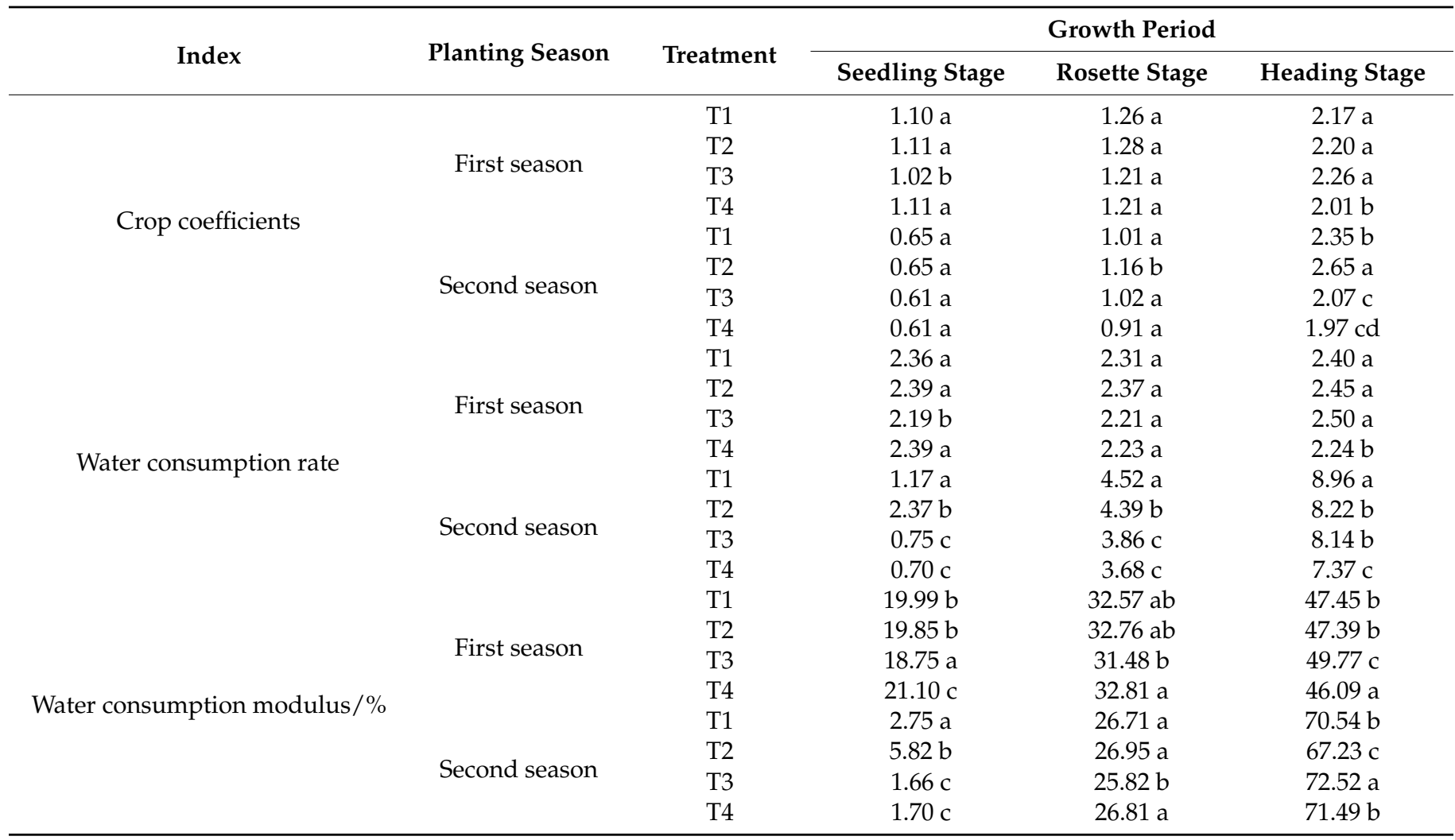

Note: The values with different letters indicate significant differences between different water treatments $(p<0.05)$.

\section{Discussion}

The IWS can sensitively reflect changes in crop weight during different growth periods at different times. The results indicate that $W_{\text {IWS }}$ and SWC have similar changing trends, and a significant correlation exists between $W_{\text {IWS }}$ and SW. The correlation in the second season is lower than that in the first season. This may be due to the different types of lettuce in the first and second seasons. The lettuce in the second season is three times as heavy as the lettuce in the first season. The daily weight gain of lettuce is ignored because it is small. However, under a similar SW, as the weight of the lettuce in the latter period increases, the variation range of $W_{\text {IWS }}$ is affected by the weight of the lettuce, resulting in scattered data and reduced correlation.

"E" refers to the amount of water transpired per unit leaf area of crops over a certain period of time. Plant water transpiration is mainly performed by the stomata of leaves, which is an important channel for the exchange of gas and water between leaves and 
the external environment. The opening and closing of stomata play an important role in plant transpiration. The results of the experiments indicate that as the irrigation volume decreases, $E$ and $g_{s c}$ also decrease. Álvarez et al. [25] believe that deficit irrigation treatment reduces stomatal conductance, which reduces the relative growth rate of plants, as well as transpiration and photosynthesis. This is because when crops suffer from soil water deficit, they cannot obtain the water required to meet the photosynthesis of plants. The photosynthesis of plants is weakened, the $g_{s c}$ of crops will decrease, and $E$ will also decrease, so as to effectively reduce the water loss of crops during transpiration. The $E$ and $g_{s c}$ of lettuce under T2 treatment are higher than those under other water treatments when the lettuce enters into the rosette and heading stages. This is because the SWC under T1 treatment is too high, which inhibits lettuce respiration, thus affecting transpiration and photosynthesis. Under T4 treatment, the SWC is too low to meet the water required for photosynthesis in lettuce, and photosynthesis is weakened [26]. In addition, the leaf area of lettuce under T2 treatment is significantly higher than that of the other treatments, which increases the $g_{s c}$ of lettuce. In the first season, the leaf area under T1, T2, T3, and T4 treatments were $464.67 \mathrm{~cm}^{2}, 481.64 \mathrm{~cm}^{2}, 473.30 \mathrm{~cm}^{2}$, and $403.30 \mathrm{~cm}^{2}$, respectively. In the second season, the leaf area under T1, T2, T3, and T4 treatments were: $2515.50 \mathrm{~cm}^{2}, 2609.63$ $\mathrm{cm}^{2}, 2104.87 \mathrm{~cm}^{2}$, and $1849.75 \mathrm{~cm}^{2}$, respectively.

Based on the IWS, the weight of lettuce was monitored in real time and continuously, and the variation law of plant evapotranspiration during the growth period was analyzed. The change of $E T_{c}$ is closely related to the change of environmental factors; hence, we further explore the relationship between $E T_{c}$ and environment (Table 5). There is a significant positive correlation between $E T_{c}$ and $\mathrm{T}$ under different water treatments. With the increase of temperature, plant evapotranspiration also increases. The results of the first and second seasons indicate that the $E T_{c}$ and water consumption of the T2 treatment are higher than those of other treatments in the rosette and heading stages. This is because with the passage of time, the leaf area of plants under T2 treatment gradually increases and photosynthesis is gradually enhanced, resulting in an increase in the $E T_{\mathcal{C}}$ of plants. This finding is similar to the results reported by Chang et al. [27].

Table 5. Correlation analysis between $E T_{c}$ and temperature.

\begin{tabular}{ccc}
\hline Planting Season & $E T_{c}$ & $\rho$ \\
\hline \multirow{2}{*}{ First season } & $\mathrm{T} 1$ & $0.854^{* *}$ \\
& $\mathrm{~T} 2$ & $0.916^{* *}$ \\
& $\mathrm{~T} 3$ & $0.798^{* *}$ \\
Second season & $\mathrm{T} 4$ & $0.882^{* *}$ \\
& $\mathrm{~T} 1$ & $0.816^{* *}$ \\
& $\mathrm{~T} 2$ & $0.829^{* *}$ \\
& $\mathrm{~T} 3$ & $0.799^{* *}$ \\
\hline
\end{tabular}

Note: ** means very significant $(p<0.01)$.

Water regulation has an important effect on plant growth and output. $K_{\mathrm{c}}$ is an important parameter for calculating crop $E T_{c}$ and reflects the influence of the biological characteristics of the crop itself, crop type, and yield level on crop water demand. Obtaining the $K_{\mathrm{c}}$ accurately is difficult. Currently, this process is mainly based on experience values [28-30]. This study analyzes the $E T_{c}$ of lettuce based on the IWS and calculates the $E T_{0}$ through the environmental parameters obtained by the weather station to analyze the daily $K_{\mathrm{c}}$ of lettuce. Studies have indicated that under different water treatments, $K_{\mathrm{c}}$ decreases as the amount of irrigation decreases. This may be because the crops under T4 treatment have been in severe water deficit for a long time during the rosette and heading stages, which inhibits the growth of crops. In the rosette and heading stages, the $K_{\mathrm{c}}$ under T2 treatment is higher than that under the other treatments, because the leaf area gradually increases over time. 
Table 6 indicates that the yield under T2 treatment has significantly increased by $11.55 \%, 5.72 \%$, and $15.80 \%$ compared with other treatments in the first season. In the second season, the yield under T2 treatment has significantly increased by $9.59 \%, 39.18 \%$, and $61.36 \%$ compared with other treatments. From the perspective of IWUE, the T2 treatment significantly increase by $11.07 \%, 0.91 \%$, and $2.16 \%$ compared with other treatments in the first season. In the second season, the T2 treatment significantly increases by $21.05 \%$, $9.89 \%$, and $13.47 \%$ compared with other treatments. From the perspective of WUE, lettuce in the second season has significantly higher water use efficiency than in the first season. This result may be because of the high temperature of the greenhouse in the second season, which increased transpiration of the lettuce, and increased the water demand, resulting in a reduction in water loss from irrigation. From the perspective of plant physiological monitoring by the IWS, the higher photosynthetic rate of T2 treatment in the first and second seasons promoted plant growth. Based on the results of the first and second seasons, it can be seen that the lower limit of soil water irrigation for lettuce planting is $80 \%$. A very high or very low water level is not good for growth and development. Excessive water irrigation will cause the soil to be in a state of water saturation for a long time, resulting in soil waterlogging, and thereby forming hypoxia deficit in the root system, which affects the growth above ground. At a very low irrigation level, the water in the soil will not reach the environment required for the growth of lettuce, thus forming soil water deficit and affecting its growth rate. This finding is consistent with the results of previous studies [31,32].

Table 6. Analysis of lettuce weight and water use efficiency under different water treatments.

\begin{tabular}{ccccc}
\hline Planting Season & Treatment & Yield/(kg) & IWUE/(kg/m $\left.\mathbf{m}^{\mathbf{3}}\right)$ & WUE/(g/kg) \\
\hline \multirow{5}{*}{ First season } & T1 & $0.381 \mathrm{~b}$ & $48.67 \mathrm{ab}$ & $56.27 \mathrm{~b}$ \\
& T2 & $0.425 \mathrm{a}$ & $54.06 \mathrm{a}$ & $61.34 \mathrm{a}$ \\
& T3 & $0.402 \mathrm{a}$ & $53.57 \mathrm{ab}$ & $59.42 \mathrm{a}$ \\
Second season & T4 & $0.367 \mathrm{c}$ & $50.02 \mathrm{~b}$ & $55.88 \mathrm{~b}$ \\
& T1 & $1.303 \mathrm{ab}$ & $65.42 \mathrm{a}$ & $83.26 \mathrm{~b}$ \\
& T2 & $1.428 \mathrm{a}$ & $79.19 \mathrm{bc}$ & $94.88 \mathrm{a}$ \\
& T3 & $1.026 \mathrm{bc}$ & $72.06 \mathrm{c}$ & $74.21 \mathrm{c}$ \\
& T4 & $0.885 \mathrm{c}$ & $69.79 \mathrm{a}$ & $69.74 \mathrm{c}$
\end{tabular}

Note: The values with different letters indicate significant differences between different water treatments $(p<0.05)$.

The results of growth physiological parameters of leaf-expansion lettuce in the first season and heading lettuce in the second season showed that the $E$ and $g_{s c}$ of lettuce in the second season were lower than those in the first season. This was because the greenhouse temperature of lettuce in the heading stage in the second season was higher than that in the first season, which inhibited $g_{s c}$ and E. The $\triangle P W_{n}$ of lettuce in the second season was faster than that in the first season, and the $K_{c}$ and $E T_{c}$ of lettuce in the second season were higher than that in the first season. This is due to the different varieties and types of lettuce in the first season and the second season. The heading lettuce in the second season was heavier than the leaf-expansion lettuce in the first season, and the greenhouse temperature in the second season was higher, so the lettuce in the second season needed more water. However, the $\triangle P W_{n}, E, g_{s c}$, yield, WUE, and other growth physiological parameters of lettuce in both of the first and second seasons were the highest under T2 treatment among the four different water treatments. The results show that T2 treatment has higher irrigation efficiency for different types of lettuce. Under the condition of water resource shortage, it can be used as a method for farmers to improve water use efficiency of lettuce.

The advantages of our IWS are as follows: 1. It can realize continuous online monitoring of SPAC, and the $K_{c}$ analytical method is established. 2. It is not affected by soil texture. Currently, dielectric method is commonly used to measure soil moisture content [33]. Due to the complexity of the soil dielectric properties of different soil types, the high-precision measurement of soil moisture at different scales is affected in the measurement process. However, the IWS measures the changes of the entire soil. So, it would not be affected by 
the soil moisture accuracy measurement. 3. It is applicable to a wide range of plants, such as ornamental potted plants, leafy vegetables, flowers, etc. However, the application of IWS is also limited by specific crops. For crops such as tomatoes and cucumbers, vine hangings are required during the growth process. The hanging vines split the load with symmetrical weight, resulting in inaccurate measurements. Therefore, IWS can be improved and optimized by adding a plant-hanging scale in future research.

\section{Conclusions}

(1) During this study, an intelligent weighing system was used to realize real-time monitoring and analysis of soil moisture weight, weight gain, transpiration rate, stomatal conductance, evapotranspiration, and crop coefficients of potted lettuce. According to the online monitoring data of the intelligent weighing system, the changes in the soilplant-atmosphere continuum at different times were reflected in real time. Simultaneously, the accuracy and feasibility of the data acquired through the intelligent weighing system were verified.

(2) Different water treatments had a significant impact on the soil-plant-atmosphere continuum of lettuce. Regarding soil, the relative system weight of the intelligent weighing system and the soil volumetric moisture content showed a consistent trend of increase and decrease, with a significant linear correlation $\left(R^{2}=0.639-0.941\right)$. Soil volumetric moisture content was higher under high moisture treatment, and the soil volumetric moisture content changed less. Regarding plants, the transpiration rate and stomata conductance of lettuce under the lowest water treatment in the first and second seasons were the lowest, which were $2.62 \mathrm{~g} \cdot \mathrm{h}^{-1}$ and $2.12 \mathrm{~g} \cdot \mathrm{h}^{-1}, 364.60 \mathrm{mmol} \mathrm{m} \mathrm{m}^{-2} \mathrm{~s}^{-1}$ and $162.74 \mathrm{mmol} \mathrm{m}^{-2} \mathrm{~s}^{-1}$, respectively. In the atmospheric environment, with an increase in temperature, lettuce transpiration gradually increases. Under T2 treatment, the evapotranspiration of lettuce was $2.70 \%, 2.35 \%, 5.21 \%$ in the first season, and $32.07 \%, 23.21 \%, 31.05 \%$ in the second season, which was higher than that of the other treatments.

(3) An appropriate irrigation low limit could increase the yield of potted lettuce. Based on research results of the first and second seasons, the stomatal conductance, transpiration rate, weight gain, individual plant weight, and irrigation water use efficiency of lettuce all improved when the irrigation low limit was $80 \%$ field capacity. Moreover, the irrigation water use efficiency of lettuce under T2 treatment in the first and second seasons was significantly increased by $11.07 \%, 0.91 \%, 8.08 \%$, and $21.05 \%, 9.89 \%, 13.47 \%$, respectively, compared with the other treatments. The yields obtained were $0.425 \mathrm{~kg}$ and $1.428 \mathrm{~kg}$, respectively.

Author Contributions: H.G., R.G. collected the meteorological data; H.G. analyzed the data; H.G wrote the paper; R.G., Z.L. and X.Z. drew the figures for this paper; Z.L., H.G., H.Y., K.S., S.Z. and $X . Z$. reviewed and edited the paper. All authors have read and agreed to the published version of the manuscript.

Funding: The research was supported by the Key Research and Development Program of Yunnan (202002AE090010), the Innovation Ability Construction Project of Beijing Academy of Agriculture and Forestry Sciences (KJCX20200430 and KJCX20210402).

Institutional Review Board Statement: The authors declare that the study did not require ethical approval.

Informed Consent Statement: The authors declare that the study did not involve humans.

Data Availability Statement: The authors declare that the study did not report any data.

Conflicts of Interest: The authors declare no conflict of interest. 


\section{Nomenclature}

$\begin{array}{ll}\text { Acronym } & \text { Meaning of Words } \\ \text { SPAC } & \text { Soil-plant-atmosphere continuum } \\ \text { IWS } & \text { Intelligent weighing system } \\ K_{\mathrm{c}} & \text { Crop coefficient } \\ \text { SWC } & \text { Soil volumetric moisture content } \\ E T_{0} & \text { Reference crop evapotranspiration } \\ V P D & \text { Vapor pressure deficit } \\ \text { WUE } & \text { Water use efficiency } \\ \text { IWUE } & \text { Irrigation water use efficiency } \\ \text { FC } & \text { Field capacity } \\ \text { W } & \text { Ins } \\ \text { SW } & \text { Soil moisture weight } \\ \text { RW } & \text { Ratio of the weight at different times of the weighing to the initial weight } \\ \Delta P W_{n} & \text { Weight gain change } \\ g_{s c} & \text { Stomatal conductance } \\ E T_{c} & \text { Crop evapotranspiration } \\ E & \text { Transpiration rate }\end{array}$

\section{References}

1. Zhang, Z.; Huang, M. Effect of root-zone vertical soil moisture heterogeneity on water transport safety in soil-plant-atmosphere continuum in Robinia pseudoacacia. Agric. Water Manag. 2021, 246, 106702. [CrossRef]

2. Che, C.; Zhang, M.; Argiriou, A.A.; Wang, S.; Du, Q.; Zhao, P.; Ma, Z. The Stable Isotopic Composition of Different Water Bodies at the Soil-Plant-Atmosphere Continuum (SPAC) of the Western Loess Plateau, China. Water 2019, 11, 1742. [CrossRef]

3. Lei, G.; Zeng, W.; Jiang, Y.; Ao, C.; Wu, J.; Huang, J. Sensitivity analysis of the SWAP (Soil-Water-Atmosphere-Plant) model under different nitrogen applications and root distributions in saline soils. Pedosphere 2021, 31, 807-821. [CrossRef]

4. García-Tejera, O.; López-Bernal, Á.; Testi, L.; Villalobos, F.J. Erratum to: A soil-plant-atmosphere continuum (SPAC) model for simulating tree transpiration with a soil multi-compartment solution. Plant Soil 2017, 418, 581. [CrossRef]

5. Dainese, R.; Lopes, B.D.C.F.L.; Fourcaud, T.; Tarantino, A. Evaluation of instruments for monitoring the soil-plant continuum Geomech. Energy Environ. 2021, 5, 100256. [CrossRef]

6. Dardanelli, J.; Ritchie, J.; Calmon, M.; Andriani, J.; Collino, D. An empirical model for root water uptake. Field Crop. Res. 2004, 87, 59-71. [CrossRef]

7. De Willigen, P.; van Dam, J.C.; Javaux, M.; Heinen, M. Root Water Uptake as Simulated by Three Soil Water Flow Models. Vadose Zone J. 2012, 11, vzj2012.0018. [CrossRef]

8. Nagahage, E.A.A.D.; Nagahage, I.S.P.; Fujino, T. Calibration and Validation of a Low-Cost Capacitive Moisture Sensor to Integrate the Automated Soil Moisture Monitoring System. Agriculture 2019, 9, 141. [CrossRef]

9. Shen, X.; Liang, J.; Zeleke, K.T.; Liang, Y.; Wang, G.; Duan, A.; Mi, Z.; Ning, H.; Gao, Y.; Zhang, J. Optimizing the Positioning of Soil Moisture Monitoring Sensors in Winter Wheat Fields. Water 2018, 10, 1707. [CrossRef]

10. Getzin, S.; Erickson, T.E.; Yizhaq, H.; Muñoz-Rojas, M.; Huth, A.; Wiegand, K. Bridging ecology and physics: Australian fairy circles regenerate following model assumptions on ecohydrological feedbacks. J. Ecol. 2021, 109, 399-416. [CrossRef]

11. Meloni, D.A.; Oliva, M.A.; Martinez, C.A.; Cambraia, J. Photosynthesis and activity of superoxide dismutase, peroxidase and glutathione reductase in cotton under salt stress. Environ. Exp. Bot. 2003, 49, 69-76. [CrossRef]

12. Buczek, J.; Migut, D.; Jańczak-Pieniążek, M. Effect of Soil Tillage Practice on Photosynthesis, Grain Yield and Quality of Hybrid Winter Wheat. Agriculture 2021, 11, 479. [CrossRef]

13. Álvarez, S.; Martín, H.; Barajas, E.; Rubio, J.A.; Vivaldi, G.A. Rootstock Effects on Water Relations of Young Almond Trees (cv. Soleta) When Subjected to Water Stress and Rehydration. Water 2020, 12, 3319. [CrossRef]

14. Liu, C.; Cui, N.; Gong, D.; Hu, X.; Feng, Y. Evaluation of seasonal evapotranspiration of winter wheat in humid region of East China using large-weighted lysimeter and three models. J. Hydrol. 2020, 590, 125388. [CrossRef]

15. Wang, T.; Melton, F.S.; Pôças, I.; Johnson, L.F.; Thao, T.; Post, K.; Cassel-Sharma, F. Evaluation of crop coefficient and evapotranspiration data for sugar beets from landsat surface reflectances using micrometeorological measurements and weighing lysimetry. Agric. Water Manag. 2021, 244, 106533. [CrossRef]

16. Tyagi, N.; Sharma, D.; Luthra, S. Determination of evapotranspiration and crop coefficients of rice and sunflower with lysimeter. Agric. Water Manag. 2000, 45, 41-54. [CrossRef]

17. Zheng, Y.; Zhao, Q.; Zhang, X.; Xue, X.; Zhong, Z.; Wang, S. Development of a multi-channel pot plant evapotranspiration measurement system based on LORA wireless technology. Water Sav. Irrig. 2020, 3, 77-84.

18. Wang, X.; Wu, Y.; Zhang, Z.; Guo, R.; Wang, L. Effects of magnetization treatment of different water sources on photosynthesis, mineral elements and yield of lettuce. J. Irrig. Drain. 2021, 40, 40-47. 
19. Wilcox, J.C. Rate of soil drainage following an irrigation: III. A new concept of the upper limit of available moisture. Can. J. Soil Sci. 1962, 42, 122-128. [CrossRef]

20. GB/T 50485-2009; Technical Specification for Micro-Irrigation Engineering. SAC: Beijing, China, 2009 ; Volume 12.

21. Liao, R.; Zhang, S.; Zhang, X.; Wang, M.; Wu, H.; Zhangzhong, L. Development of smart irrigation systems based on real-time soil moisture data in a greenhouse: Proof of concept. Agric. Water Manag. 2021, 245, 106632. [CrossRef]

22. Zhang, F.; Liu, Z.; Zhangzhong, L.; Yu, J.; Shi, K.; Yao, L. Spatiotemporal Distribution Characteristics of Reference Evapotranspiration in Shandong Province from 1980 to 2019. Water 2020, 12, 3495. [CrossRef]

23. Halperin, O.; Gebre, A.; Wallach, R.; Moshelion, M. High-throughput physiological phenotyping and screening system for the characterization of plant-environment interactions. Plant J. 2017, 89, 839-850. [CrossRef] [PubMed]

24. González-Esquiva, J.; Oates, M.; García-Mateos, G.; Moros-Valle, B.; Martínez, J.M.M.; Ruiz-Canales, A. Development of a visual monitoring system for water balance estimation of horticultural crops using low cost cameras. Comput. Electron. Agric. 2017, 141, 15-26. [CrossRef]

25. Álvarez, S.; Sánchez-Blanco, M.J. Changes in growth rate, root morphology and water use efficiency of potted Callistemon citrinus plants in response to different levels of water deficit. Sci. Hortic. 2013, 156, 54-62. [CrossRef]

26. Sánchez-Blanco, M.J.; Álvarez, S.; Navarro, A.; Bañón, S. Changes in leaf water relations, gas exchange, growth and flowering quality in potted geranium plants irrigated with different water regimes. J. Plant Physiol. 2009, 166, 467-476. [CrossRef]

27. Chang, X.; Zhao, W.; Zhao, A.J. Dynamics of leaf area index and its relationship with water consumption of Populus chinensis in the middle reaches of heihe River. Glaciol. Geocryol. 2006, 1, 85-90.

28. Irmak, S.; Irmak, A.; Allen, R.; Jones, A.J. Solar and net radiation-based equations to estimate reference evapotranspiration in humid climates. J. Irrig. Drain. Eng. 2003, 129, 336-347. [CrossRef]

29. Pereira, L.; Paredes, P.; López-Urrea, R.; Hunsaker, D.; Mota, M.; Shad, Z.M. Standard single and basal crop coefficients for vegetable crops, an update of FAO56 crop water requirements approach. Agric. Water Manag. 2021, 243, 106196. [CrossRef]

30. Saitta, D.; Vanella, D.; Ramírez-Cuesta, J.M.; Longo-Minnolo, G.; Ferlito, F.; Consoli, S. Comparison of Orange Orchard Evapotranspiration by Eddy Covariance, Sap Flow, and FAO-56 Methods under Different Irrigation Strategies. J. Irrig. Drain. Eng. 2020, 146, 05020002. [CrossRef]

31. Fan, Y.; Massey, R.; Park, S.C. Multi-Crop Production Decisions and Economic Irrigation Water Use Efficiency: The Effects of Water Costs, Pressure Irrigation Adoption, and Climatic Determinants. Water 2018, 10, 1637. [CrossRef]

32. Liu, Y.; Li, S.; Chen, F.; Yang, S.; Chen, X. Soil water dynamics and water use efficiency in spring maize (Zea mays L.) fields subjected to different water management practices on the Loess Plateau, China. Agric. Water Manag. 2010, 97, 769-775. [CrossRef]

33. Bobrov, P.P.; Belyaeva, T.A.; Kroshka, E.S.; Rodionova, O.V. Soil Moisture Measurement by the Dielectric Method. Eurasian Soil Sci. 2019, 52, 822-833. [CrossRef] 